
http://www.anpad.org.br/bar

\title{
The Influence of Adaptation and Standardization of the Marketing Mix on Performance: a Meta-Analysis
}

\author{
Vinícius Andrade Brei * \\ E-mail address: brei@cse.ufsc.br \\ Universidade Federal de Santa Catarina - UFSC \\ Florianópolis, SC, Brazil. \\ Lívia D'Avila \\ E-mail address: liviacd@unisinos.br \\ Universidade do Vale do Rio dos Sinos - UNISINOS \\ Porto Alegre, RS, Brazil. \\ Luis Felipe Camargo \\ E-mail address: feliperiehs@yahoo.com.br \\ Universidade do Vale do Rio dos Sinos - UNISINOS \\ Porto Alegre, RS, Brazil. \\ Juliana Engels \\ E-mail address: ju.engels@terra.com.br \\ Pontifícia Universidade Católica do Rio Grande do Sul - PUCRS \\ Porto Alegre, RS, Brazil.
}

* Corresponding author: Vinícius Andrade Brei

CSE/CAD/UFSC, Campus Universitário Reitor João David Ferreira Lima, Trindade, Florianópolis, SC, 88040900, Brazil.

Copyright (C) 2011 Brazilian Administration Review. All rights reserved, including rights for translation. Parts of this work may be quoted without prior knowledge on the condition that the source is identified. 


\begin{abstract}
This article analyzes the relationship between strategies of standardization and adaptation of the marketing mix and performance in an international context. We carried out a meta-analysis on a sample of 23 studies published between 1992 and 2010. The sample was analyzed based on measures of the effect size (ES) - or the strength of the relation (Wolf, 1986) - between standardization/adaptation and performance. The results suggest the existence of a medium strength (ES ranging from .133 to .209) for the relationship considered. The results support the existence of a positive impact of both marketing mix adaptation and standardization on performance. However, our results suggest that companies should slightly emphasize the marketing mix adaptation (ES mean $=.168)$ instead of standardizing it $(\mathrm{ES}$ mean $=.134)$ when entering in a new international market. Results also indicate that, among the adaptation choices, price $(E S=.209)$ should be the first element of the marketing mix to be adapted, followed by promotion $(\mathrm{ES}=.155)$, product $(\mathrm{ES}=.154)$, and distribution $(\mathrm{ES}=.141)$. Finally, we suggest some new research paths, such as the use of quantitative methods to compare degrees of adaptation to be applied to different segments, regions, and sectors, among other suggestions.
\end{abstract}

Key words: standardization; adaptation; marketing; performance; meta-analysis. 


\section{Introduction}

Considering the current globalized market, companies have seen the internationalization of their activities as a way to remain competitive. Decision-making concerning the international marketing mix has become critical, especially because of the influence this arrangement has on performance. Thus, many authors have pointed out the need for research that relates standardization and adaptation to performance (Calantone, Cavusgil, Schmidt, \& Shin, 2004; Dow, 2006; Florin \& Ogbuehi, 2004; Julian \& O'Cass, 2004; Shoham, 2002). Despite such encouragement, no consensus on the relationship between the two former and the latter has yet been reached.

The literature as to which is the best decision is still inconclusive, considering the type of effect (positive or negative) of standardization and adaptation on performance. Some authors believe that a relationship between standardization and performance does not exist (Samiee \& Roth, 1992). Others, in contrast, have found a positive link between the adaptation of the product and its performance (e.g. Calantone et al., 2004; Calantone, Kim, Schmidt, \& Cavusgil, 2006; Cavusgil \& Zou, 1994; Lee \& Griffith, 2004). Hence, the agreement about the effects of these strategies on performance represents a gap in the literature (Zou \& Cavusgil, 2002), which this research aims to fulfill.

Although companies' strategies may influence performance, the findings so far are not conclusive, especially those that deal with the relationships between the marketing mix and performance (Shoham, 2002). Besides, contradictory and confusing results have emerged from the literature, turning marketers' decision making into a difficult course of action. This discrepancy clamors for the development of more concise and accurate theories, methods, and strategic frameworks, since marketers need to understand under which circumstances each strategy turns out to be more suitable, and under which conjunctures such strategies lead to positive performance (Calantone et al., 2004).

Also, we identify the need for a statistical analysis of a large collection of analyzed data (that is, previous primary research) for the purpose of integrating the findings, and providing methodological rigor to the literature on this specific subject. These are the goals of meta-analyses, a statistical method generally centered on the relationship between one explanatory and one response variable. This relationship, the effect of $\mathbf{X}$ on $\mathbf{Y}$, defines the analysis (DeCoster, 2004).

Therefore, the aims of this study are: (a) to carry on a meta-analysis of previous empirical research pertaining to the role of the strategies of standardization and adaptation of the marketing mix and performance in an international context; and (b) suggest to marketers courses of action based on the analysis of these strategies and their relationships with performance.

Other studies have previously tried to understand the relationships between the marketing mix elements and performance (e.g. Leonidou, Katsikeas, \& Samiee, 2002; Shoham, 2002; Theodosiou \& Leonidou, 2003), but they had different goals from ours. Leonidou, Katsikeas and Samiee (2002) proposed a study in which a meta-analysis was also conducted to evaluate the relationships between the marketing mix elements and performance, but their study did not consider adaptation and standardization of the mix elements, and was also based on a more complex framework, which included other variables and antecedents. Shoham (2002) analyzed the degree of standardization of the marketing mix in relation to a satisfaction-based performance measure;but he specifically considered the export marketing mix's degree of standardization and export planning impact on export performance. That is, as opposed to our study, he tested the degree of standardization/adaptation strategy, and not as a distinct strategy, as we treat it. Finally, Theodosiou and Leonidou (2003) have also studied the relationships between the marketing mix and performance. However, their article is an integrative view of the literature, not a meta-analysis. Besides, they evaluate the antecedents of the marketing mix and their impact on performance through a more complex combination of these elements. In short, our study is different from these previous ones because we carry on a meta-analysis that investigates the relationship between the role of the strategies of standardization and adaptation of the marketing mix and performance in an international context. 
This paper unfolds as follows: we first briefly review the literature on standardization and adaptation of the marketing mix, and also on organizational performance. Based on this literature review we draw the paper's hypotheses, followed by the methodology, main descriptive and quantitative results. Next we discuss our findings, drawing conclusions for the theory and for the practice of marketing. Finally, we discuss the limitations of our work, and present some suggestions for future research.

\section{Theoretical Background}

The expansion of a company into foreign markets demands a precise decision making process, because there are many aspects that influence such an internationalization process ${ }^{(1)}$. One of the most important decisions concerns the marketing mix. By developing an adequate marketing mix, organizations can satisfy the needs of their target market and reach their organizational objectives, improving performance. Therefore, products that enter a market for the first time have to be tailored to the characteristics of that country, since it is not likely that a single strategy will be able to satisfy all consumers, especially taking into account the existing heterogeneity of the markets (Vignali, 2001). So the company deliberates on which is the best strategy for the marketing mix - adaptation or standardization.

\section{Adaptation versus standardization}

The main goal of a global strategy is management of the great differences that emerge beyond domestic borders (Ghemawat, 2007a). Global marketing is not a synonym for standardization in marketing processes. Although each element of this process is susceptible to standardization, this can be only one of the strategies adopted by the company.

The strategies of international marketing follow three different perspectives. The first is the concentration-dispersion perspective, which analyzes the organizational structure of the company. The second is the integration-independence perspective, which has to do with the competitive process faced by companies. The third - the focus of this article - deals with the adaptation-standardization perspective, which is related to the degree of adjustment or standardization of the marketing mix elements (Lim, Acito, \& Rusetski, 2006; Zou \& Cavusgil, 2002).

From the moment a company decides to extend its activities into foreign markets, it should settle on either standardizing or adapting the marketing mix. This can be done when the organization applies a single strategy in all the countries, or customizes the elements to each market (Jain, 2007; Vrontis \& Kitchen, 2005; Vrontis \& Papasolomou, 2005). The company's decision to standardize or to adapt its strategies is fundamental, since it influences the organization's fundamental approach to business and how it will compete (Ang \& Massingham, 2007).

The debate concerning the standardization or adaptation of the marketing mix in different markets has been object of many studies (see, for example, Levitt, 1983, 1986; Quelch \& Hoff, 1986; Sorenson \& Wiechmann, 1975; Vrontis \& Kitchen, 2005; Vrontis \& Papasolomou, 2005). Studies about standardization started in the 1960s, when Elinder (1965) first analyzed the standardization of promotion, been followed by studies about product. Nowadays standardization studies comprise all elements of the marketing mix - product, promotion, price and distribution (Özsomer \& Simonin, 2004; Vrontis \& Kitchen, 2005), although promotion and product have received more attention (e.g. Baalbaki \& Malhotra, 1993; Kotler, 1986; Laroche, Kirpalani, Pons, \& Zhou, 2001; Levitt, 1983; Papavassiliou \& Stathakopoulos, 1997; Samiee \& Roth, 1992).

Broadly speaking, standardization has been analyzed under two perspectives - standardization of marketing processes and marketing programs. The former is concerned with the philosophy, 
principles, and technology used in planning and implementing marketing decisions. The latter - the purpose of this study - refers to the elements of the marketing mix.

Despite some studies that have analyzed the standardization concept (e.g. Jain, 1989; Özsomer, Bodur, \& Cavusgil, 1991), its consensual understanding has yet to be established (Ryans, Griffith, \& White, 2003). Standardization is the use of the same marketing program in different countries or regions, regarding the product offered, the promotion employed, the price established and the distribution process chosen (Elinder, 1965; Jain, 1989, 2007; Levitt, 1983; Özsomer \& Simonin, 2004; Roostal, 1963; Sands, 1979; Szymanski, Bharadwaj, \& Varadara, 1993; Viswanathan \& Dickson 2007).

The main argument supporting the standardization strategy is the belief that the world is becoming more and more homogeneous, especially as a result of the advances in communication and technology (Jain, 1989; Levitt, 1983). As a consequence, tastes and cultures are becoming homogeneous; world consumers are sharing preferences, needs, desires and demands (Jain, 1989, 2007; Levitt, 1983; Vrontis \& Papasolomou, 2005). This similarity of demands, along with convergent cultures and the lowering of barriers, would make it possible for companies to sell more standardized products, with standardized marketing programs (Zou \& Cavusgil 2002).

Standardization, thus, allows focus on common segments, bringing economy of scale and more consistent promotions. Papavassiliou and Stathakopoulos (1997) and Levitt $(1983,1986)$ offer four main reasons for such benefits: (a) standardization allows the corporation to preserve a consistent image and identity throughout the world; (b) it reduces uncertainty among buyers who travel frequently; (c) it allows the company to develop a single advertising campaign for different markets; and (d) it results in sizeable savings in advertising, such as illustrative material, media and advertising production costs. Despite such economies of scale, cultural and socio-economic differences among countries seem to hinder the standardization strategy, sometimes requiring adjustments to the market, and demanding additional expenses to justify the standardization decision (Kogut, 1989).

In any case, the decision on standardizing or adapting must be based on the possible financial returns and risks involved for each alternative (Sands, 1979). The option for global standardization will be appropriate only up to the point when a positive influence is present on the company's performance (Samiee \& Roth, 1992). However, immense differences between markets do exist, even in industrialized nations. In order to address these differences, changes in design, packaging, price, or distribution of goods might be necessary. Moreover, viability, communication costs, media habits, differences in the range of distribution channels, intermediaries, financial resources and know-how may also cause trouble (Samiee \& Roth, 1992). In short, total standardization can lead the company to fail when it comes to taking care of local consumers' needs, and might result in its alienation from the local market (Newburry \& Yakova, 2006). In this case, the standardization arguments fall apart especially when considering the peculiar differences between consumers, administrators and nations and adaptation becomes an option (Shoham, 1999).

For the purposes of this paper, we define adaptation of the product as the degree to which its elements (brand, design, label, product line, and quality) are adapted to the external markets in order to adjust to the differences in the environment, consumer behavior, standards of use, and competitiveness. Thus, adaptation involves the use of specific strategies in each market, where the organization adapts its marketing mix to each environment (Ang \& Massingham, 2007; Zou, Andrus, \& Norvell, 1997). It involves the customization of strategies for different regions, based upon assorted factors. Sands (1979) defines adaptation as the use of marketing strategies with no common elements. That is, the company should always observe national identity, language, tastes, and preferences. Defenders of adaptation believe that markets are subject to changing macro-environmental issues, such as climate, language, race, occupations, topography, education, tastes, legal and political barriers and socio-economic matters (Baalbaki \& Malhotra, 1993; Jain, 1989).

Pricing adaptation focuses on adjustment to the external market for many reasons, such as economic, political, and legal issues, price controls, transportation costs, market structures, demands, 
rates, taxes, trade barriers, pricing practices, etc. Distribution adaptation is associated with the adjustment of the firm's channels to the foreign market, including the criteria for selection of the distribution system, transportation, budget and network. Finally, promotion is linked to the adjustments in the campaign (e.g. idea/theme, media channels, objectives, budget, etc.) made for the new market in comparison with the domestic one (Lages \& Montgomery, 2004; Leonidou et al., 2002).

Some understand that the core question is not whether to standardize or to adapt marketing strategies, but how much to adapt them (Cavusgil \& Zou, 1994; Jain, 1989, 2007). Cavusgil, Zou, and Naidu (1993) suggest that the degree of adaptation of the product and promotion is significantly influenced by the firm's characteristics, products and industry, as well as by the foreign market's characteristics. Thus, many authors reject the extreme use of only one or another strategy. Instead, they believe that there is a need for the simultaneous use of both strategies, where the degree of standardization or adaptation should depend on internal and external factors (Cavusgil, Zou, \& Naidu, 1993; Jain, 1989; Vrontis \& Papasolomou, 2005; Walters, 1986). For them, multinational companies should be simultaneously focused on the facets that need global standardization as well as on those requiring a local variation (Vrontis, 2003); incorporating elements of both strategies, standardizing the elements that bring benefits, and adapting those that satisfy the needs of the local market (Vrontis \& Kitchen, 2005). Next we briefly review the theory about the dependent variable of our meta-analysis performance.

\section{Performance}

Organizational performance is a complex and multifaceted phenomenon that is comprised by different views of a company, a division, or a project success. Carneiro, Silva, Rocha and Hemais (2005) affirm that it is not possible to describe performance success using only one perspective and/or a single metric. For them, different perspectives must be taken into account when evaluating if success has been reached or not. This is why success can be understood through different perspectives (e.g. degree, level, etc.), and not as single 'yes' or 'no' result (Carneiro, Silva, Rocha, \& Hemais, 2005).

Despite this view that performance is a complex and multifaceted phenomenon, there are many authors who have tried to define it. A few of these definitions have been widely studied and applied both on the academic and on the managerial fields. For example, Kaplan and Norton's (1992) Balanced Scorecard conceptualizes performance by considering four different views: financial, customer, internal business process, and learning and growth; Barney (1996) considers four different approaches to performance: firm survival, accounting measures, multiple stakeholders' views, and present-value measurements; Ginsberg (1984) focuses on how to measure performance, analyzing the importance of data sources, format, and analysis techniques.

After studying over 150 articles about performance that have been published in Strategic Management, International Business, Marketing, and New Business journals, Carneiro et al. (2005) proposed a robust integrative model of performance appraisal. Strategic Management, International Business, Marketing, and New Business, and proposed a robust integrative model of performance appraisal. Their model considered, first, conceptual macro-dimensions (i.e., performance definitions); and second, methodological macro-dimensions (i.e., focused on data collection procedures) of performance. Their conceptual macro-dimensions proposition considers stakeholders' views, classes of measurements, perspective of reference (absolute or relative), and temporal orientation (transversal/static, or longitudinal/dynamic). The methodological macro-dimensions include level of analysis (business unit, company, specific combinations, etc.), data objectivity, and data format.

Broadly speaking, the international marketing literature does not consider the performance construct in such a robust stance as Carneiro et al. (2005). Instead, we have identified two broad dimensions: financial (all value-related affairs) and strategic (procedures to be adopted, such as segmentation, target and positioning) (Cavusgil \& Zou, 1994; Julian, 2003; Leonidou et al., 2002; Okazaki, Taylor, \& Zou, 2006; Samiee \& Roth, 1992; Zou \& Cavusgil, 2002). For the sake of 
simplicity, in this paper we will not differentiate between those two performance dimensions, but will consider it as a single-dimensional construct.

Despite being a limitation, our choice is not uncommon in the literature. Carneiro et al. (2005) have found that usually one or just a few performance facets are used in most of the studies, and sometimes they can even be measured incorrectly. The reason for this is that there are always conceptual, methodological, operational, and practical limitations in each and every work that drive authors to emphasize just one or a few perspectives concerning performance. This is precisely the case with this paper. Even considering the relevance of a more robust evaluation of the performance construct, our goal is not to discuss the performance construct in depth, but to analyze the impact standardization and adaptation strategies of the marketing mix have on performance. Our choice of using a more generic and broader view of the performance construct, thus, has been made to allow a more comprehensive meta-analysis concerning the impact of the international marketing strategies. Therefore, our theoretical appraisal of the performance construct is focused on how the international marketing papers have analyzed it, what can be different - one might say less accurate - as compared to papers that have dealt exclusively with the performance construct.

Considering the relationship between performance and the marketing mix - as treated in the international marketing literature - many studies have analyzed the relationships between product and performance (Doole, Grimes, \& Demack, 2006; Julian, 2003; Julian \& O'Cass, 2004; Kazem \& Heijden, 2006; Kemppainen, Vepsäläinen, \& Tinnilä, 2008; Ogunmokun \& Esther, 2004), price and performance (Colpan, 2006; Doole et al., 2006; Myers \& Harvey, 2001; Myers, Cavusgil, \& Diamantopoulos, 2002), distribution and performance (Amine \& Cavusgil, 2001; McNaughton, 2002; Myers \& Harvey, 2001), and promotion and performance (Amine \& Cavusgil, 2001; Francis \& Collins-Dodd, 2004; Shamsuddoha \& Ali, 2006).

Other articles considered the marketing mix as a single construct, analyzing the four mix elements all together (e.g. Johnson \& Arunthanes, 1995; Julian \& O'Cass, 2004; O'Donnell \& Jeong, 2000; Özsomer \& Simonin, 2004; Schilke, Reimann, \& Thomas, 2009; Zou \& Cavusgil, 2002; Wua \& Cheng, 2009). In spite of so many studies that have analyzed the relationship between the marketing mix elements and performance, we have not found articles that have analyzed the impact of standardization and adaptation of all four elements of the marketing mix - analyzed separately, in only one article - on performance. The hypotheses we draw next try to overcome such gap.

\section{Hypotheses}

We developed the hypotheses of the study based on the recent literature on the relationships between the marketing mix and performance, moderated by the adaptation and standardization variables. As independent variables, we consider the elements of the marketing mix, namely, product, price, promotion and distribution; as the dependent variable we considered the company's performance; as moderators, adaptation and standardization. While the majority of the studies present a significant influence from the standardization of the marketing mix on the performance of a company (e.g. Conant \& White, 1999; Florin \& Ogbuehi, 2004; Szymanski et al., 1993), others found a non-significant or inverse relationship (e.g. Julian, 2003; Samiee \& Roth, 1992). Thus, the following hypotheses are proposed:

H1a: the standardization of the company's product, in international markets, affects its performance positively.

H1b: the standardization of the company's promotion, in international markets, affects its performance positively.

H1c: the standardization of the company's distribution, in international markets, affects its performance positively. 
H1d: the standardization of the company's pricing, in international markets, affects its performance positively.

We have found similar analysis in articles involving adaptation. Some of these results demonstrate the positive influence of the moderator variable on performance (e.g. Conant \& White, 1999; Florin \& Ogbuehi, 2004; Lages, Abrantes, \& Lages, 2008; Leonidou et al., 2002; Sousa \& Lengler, 2009). Some other studies identified a negative or insignificant influence (e.g. Julian, 2003; Julian \& O'Cass, 2002; Lages \& Montgomery, 2005; O'Cass \& Julian, 2003; Shoham, 1999; Tantong, Karande, Nair, \& Singhapakdi, 2010). Therefore, the following hypotheses are proposed:

H2a: the adaptation of the company's product, in international markets, affects its performance positively.

H2b: the adaptation of the company's promotion, in international markets, affects its performance positively.

H2c: the adaptation of the company's distribution, in international markets, affects its performance positively.

H2d: the adaptation of the company's pricing, in international markets, affects its performance positively.

\section{Method}

Considering the inconclusive nature of the literature on the subject, we have adopted a metaanalytical procedure. As Farley, Lehmann and Sawyer (1995) argue, the confrontation between the theory and the knowledge accumulated after many studies is essential to the progress of the research. A meta-analysis aims to contribute to the growth of the literature concerning a certain topic, as well as its applicability and possibility for generalization, which is an important tool for reaching a consensus. Therefore, the aim is to group conflicting results on a specific subject, where the researcher conducts an analysis of the analyses (Wolf, 1986).

\section{Data collection}

Some criteria were initially adopted to identify studies that would be incorporated into the sample. First, to be part of the meta-analysis, the study should consider the relationship between standardization and adaptation - of at least one of the elements of the marketing mix - and performance. Second, considering the diversity of concepts referring to performance, the selected articles should relate performance to the results of the firm's activities, whether economic or behavioral. Third, we have not adopted any kind of restrictions about the business unit or variable analyzed - i.e., headquarters or branch offices, number of operating countries, industrial diversity, country of origin, or foreign experience. This is because our main goal was not to analyze social, political or environmental variables that may interfere in the relationships. Instead, our focus was to consider the strategic elements of standardization and adaptation of the marketing mix as moderators of performance. Last, the articles should be cross-sectional or longitudinal, due to the statistical analysis to be conducted.

We carried out the data collection through a key-word search in major electronic databases such as EBSCO and Proquest. The keywords were: marketing, performance, standardization, adaptation, product, price, promotion and distribution. No restrictions about the starting data of publication were made, and the ending data was the year 2011. Considering these criteria, we have found a total of 63 articles published in the major marketing and business journals, such as Journal of Marketing, Journal of Business Research, Journal of Advertising, International Journal of Research in Marketing, 
European Journal of Marketing, Journal of Marketing Management, Journal of Asia Pacific Marketing, Journal of Product Innovation Management, Journal of International Business Studies, International Marketing Review, Applied Economics Letters, Journal of Marketing Theory and Practice and Journal of International Marketing.

To be included in our final sample, the article should present at least one tested hypothesis relating marketing mix elements with performance. Also, each article should be based on quantitative data, containing all minimum information required for a meta-analytical statistical calculus (e.g. sample size, valid sample, p_value). Each selected article was read and analyzed in order to check for the minimum necessary information. Based on these criteria, 23 of the original 63 studies qualified for the meta-analysis, therefore constituting our final sample (see Table 1).

\section{Data analysis}

Procedures employed in meta-analysis allow a quantitative examination and synthesize the literature about a certain issue. There are two kinds of procedures. The first measures the effect size or the strength of the relationship (Wolf, 1986). It is observed that the great majority of meta-analytical studies calculate the effect size. This refers to a set of indexes that measure the magnitude of one specific relation, i.e., the strength of the relationship between the independent and dependent variables (Jitpaiboon \& Rao, 2007). The second procedure, alternatively, focuses on testing the statistical significance of a relationship through combined results from different studies, which is known as a combined test (Wolf, 1986). We have used the first procedure - the effect size - to test our hypothesis, as it is suitable for the quantitative calculus of existence and strength of a relationship between variables.

We have selected, tabulated, and analyzed data from our sample. First, we conducted a descriptive analysis to detail the major characteristics of each article of our sample (see Table 1). Next we calculated the effect size to verify the strength of the relationships between the moderator variables (standardization and adaptation of the marketing mix) and performance. Then, we converted the statistical analyses of the original studies into a common metric - e.g. p_values of each hypothesis into $\mathbf{z}$ scores. It is important to note that the $\mathrm{z}$ score was calculated considering the $\mathrm{p}$ _value and the inverse of the standard cumulative probability distribution, a formula available on a number of statistical software like MS Excel. The scores were then used to calculate the effect size $\mathbf{r}$, as shown in the formula bellow (Cooper \& Hedges, 1999):

$$
r=\frac{z}{\sqrt{N}}
$$

where $\mathrm{z}$ is the $\mathrm{z}$ score and $\mathrm{N}$ is the sample, i.e., the number of questionnaires that were returned and had been used (that is, the valid sample).

In order to test our hypotheses, we calculated the mean value of the correlations of those studies found on our sample that examined equivalent hypothesis. These mean values - representing the effect size - were calculated as follows (Wolf, 1986):

$$
\bar{r}=\frac{\Sigma r}{n}
$$

where $r$ is the correlation coefficient and $\mathrm{n}$ is the sample, i.e., the number of studies that supports each hypothesis. We have adopted this procedure to determine the strength of the relationships between the adaptation or standardization of one or more elements of the marketing mix and the performance. 


\section{Results}

\section{Descriptive analysis}

The first analysis refers to the descriptive characteristics of the final sample. As shown in Table 1 , from the 23 analyzed studies, only 4 were carried out in the $1990 \mathrm{~s}$, while the other 19 were published after 2000. Geographically, 16 studies were held in either Europe or North America. In all, 27 different samples were used in the 23 studies, 12 of them composed of up to 500 respondents, and 11 of them with more than 500 respondents. Despite the fact that samples from studies B, E, M, N, P, $\mathrm{R}$ and $\mathrm{W}$ had more than 1000 respondents, the average number of respondents was 798 .

The average number of returned questionnaires was 244, although 13 studies did not specify this number on at least one of its samples. In one of them (study L) this characteristic was not considered, since all respondents were personally interviewed. In the total, 5 studies did not specify the percentage of usable questionnaires. Again, this criterion was not employed for study L, due to the abovementioned reason. For the remaining 17 studies, the average number of usable questionnaires was 229 . Excluding study L, the response rate average was $40 \%$. Only 12 studies presented the number of different industries involved. All studies - except study L - applied the non-bias test. Data were collected by mail in 20 out of 23 studies; the 3 remaining gathered data through personal interviews, or did not inform of the data collection method (see Table 1).

Table 1

Final Sample Characteristics

\begin{tabular}{|c|c|c|c|c|c|c|c|c|c|c|c|}
\hline 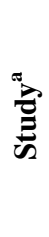 & 宔 & 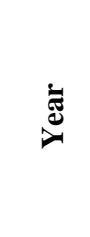 & 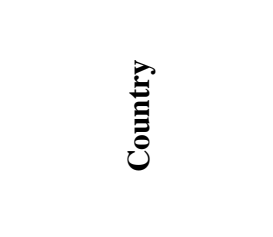 & 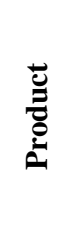 & 竞 & 咅 & $\begin{array}{l}\text { D্ّ } \\
\stackrel{D}{D}\end{array}$ & 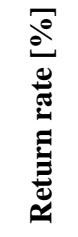 & 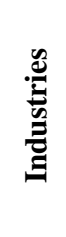 & 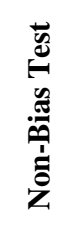 & 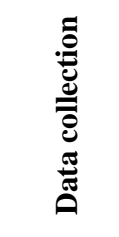 \\
\hline A & Lee and Griffith & 2004 & Korea & $\mathrm{C} / \mathrm{I}$ & 180 & 63 & 58 & 32,2 & 1 & yes & Mail \\
\hline $\mathrm{B}$ & O'Cass and Julian & 2003 & Australia & $\mathrm{C} / \mathrm{I}$ & 1132 & $\mathrm{NSa}$ & 293 & 25,8 & 7 & yes & Mail \\
\hline $\mathrm{C}$ & O'Donnell and Jeong & 2000 & $\begin{array}{l}\text { USA; UK; Canada; } \\
\text { Japan and Germany }\end{array}$ & I & 426 & NS & 110 & 26,0 & 2 & yes & Mail \\
\hline $\mathrm{D}$ & Özsomer and Simonin & 2004 & Turkey & $\mathrm{C} / \mathrm{I}$ & 253 & 180 & NS & 71,0 & NS & yes & Mail \\
\hline $\mathrm{E}$ & Johnson and Arunthanes & 1995 & USA & $\mathrm{C} / \mathrm{I}$ & 1300 & 224 & 208 & 18,0 & NS & yes & Mail \\
\hline $\mathrm{F}$ & Shoham & 1999 & Israel & $\mathrm{C} / \mathrm{I}$ & 463 & 98 & NS & 21,2 & 18 & yes & Mail \\
\hline $\mathrm{G}$ & Samiee and Roth & 1992 & USA & $\mathrm{C} / \mathrm{I}$ & 322 & 147 & NS & 46,0 & 12 & yes & Mail \\
\hline $\mathrm{H}$ & Zou and Cavusgil & 2002 & USA & $\mathrm{C} / \mathrm{I}$ & 422 & 126 & 374 & 33,6 & 23 & yes & Mail \\
\hline \multirow{3}{*}{ I } & \multirow{2}{*}{ Calantone et al. } & \multirow{2}{*}{2004} & \multirow{2}{*}{ USA } & \multirow{2}{*}{ NS } & 541 & NS & 239 & 47,0 & NS & yes & Mail \\
\hline & & & & & 700 & 325 & 303 & 43,0 & NS & yes & Mail \\
\hline & & & USA & NS & 541 & NS & 239 & 47,0 & NS & yes & Mail \\
\hline \multirow[t]{2}{*}{$\mathrm{J}$} & Calantone et al. & 2006 & Japan & NS & 500 & NS & 145 & 29,0 & NS & yes & Mail \\
\hline & & & Korea & NS & 700 & 325 & 303 & 43,0 & NS & yes & Mail \\
\hline $\mathrm{K}$ & Dow & 2006 & Autralia & NS & 207 & NS & 100 & 48,0 & NS & yes & Mail \\
\hline $\mathrm{L}$ & Cavusgil and Zou & 1994 & USA & $\mathrm{C} / \mathrm{I}$ & 202 & $N A^{b}$ & NA & NA & 16 & NA & Personal \\
\hline
\end{tabular}


Table 1 (continued)

\begin{tabular}{|c|c|c|c|c|c|c|c|c|c|c|c|}
\hline 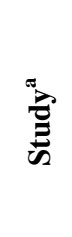 & 总 & ప્兀 & 总 & $\begin{array}{l}\grave{\Xi} \\
\stackrel{0}{0} \\
D\end{array}$ & 竞 & 忢 & D্ّ & 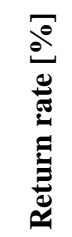 & & 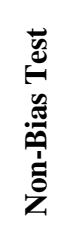 & 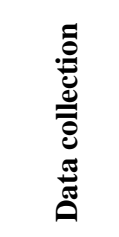 \\
\hline M & Lages and Montgomery & 2005 & Portugal & NS & 2500 & 519 & NS & 22,0 & NS & yes & Mail \\
\hline $\mathrm{N}$ & Julian and O'Cass & 2004 & $\begin{array}{c}\text { Australia; UK and } \\
\text { France }\end{array}$ & $\mathrm{C} / \mathrm{I}$ & 1132 & NS & 293 & 25,8 & 7 & yes & Mail \\
\hline $\mathrm{O}$ & Okazaki et al. & 2006 & $\begin{array}{l}\text { Germany; Italy and } \\
\text { Netherlands }\end{array}$ & NS & 564 & 116 & 107 & 23,5 & NS & yes & Mail \\
\hline $\mathrm{P}$ & Lages and Montgomery & 2004 & Portugal & NS & 1967 & 459 & 413 & 23,3 & NS & yes & Mail \\
\hline Q & Lages et al. & 2008 & Portugal & I & 93 & NA & 88 & 95 & NS & yes & Personal \\
\hline $\mathrm{R}$ & Schilke et al. & 2009 & USA & $\mathrm{C} / \mathrm{I}$ & 2549 & NA & 489 & 19 & 7 & yes & Mail \\
\hline $\mathrm{S}$ & Chung & 2009 & UK & $\mathrm{C} / \mathrm{I}$ & 233 & NA & 78 & 33 & NA & yes & Mail \\
\hline $\mathrm{T}$ & Sousa and Lengler & 2009 & Brazil & $\mathrm{C} / \mathrm{I}$ & 1000 & NA & 201 & 20.1 & NA & yes & Mail \\
\hline $\mathrm{U}$ & Wua and Cheng & 2009 & NA & $\mathrm{C} / \mathrm{I}$ & 345 & NA & NA & NA & 4 & NA & NA \\
\hline $\mathrm{V}$ & $\begin{array}{l}\text { Hultman, Robson and } \\
\text { Katsikeas }\end{array}$ & 2009 & Sweden & $\mathrm{C} / \mathrm{I}$ & 561 & 401 & 341 & 60.8 & 1 & yes & Mail \\
\hline $\mathrm{W}$ & Tantong et al. & 2010 & Thailand & $\mathrm{C} / \mathrm{I}$ & 2200 & 252 & 252 & 11.9 & 13 & yes & Mail \\
\hline Meaı & & & & & 809 & 249 & 232 & 40 & 9 & & \\
\hline
\end{tabular}

Note. ${ }^{a}$ Each letter corresponds to one study

$\mathrm{C}=$ consumer $\mathrm{I}=$ industrial; $\mathrm{NS}=$ not specified; $\mathrm{NA}=$ not applicable.

\section{Quantitative analysis}

In order to test our hypotheses, we converted all p_values found in the studies into $\mathbf{z}$ scores. The p_values, $\mathbf{z}$ scores and $\boldsymbol{r}$ correlations for the sample are presented on Table 2. Some articles did not show the exact $\mathrm{p}_{-}$value, but only an indication of the reference value $\left(e . g . \mathrm{p}_{-}\right.$value $\left.<0,01\right)$. In this case, we have assumed the $p_{-}$value as equal to the reference value. Studies $\bar{A}$, E, and $\mathrm{K}$ presented hypotheses followed by specific p_values; we converted these values into $\mathbf{z}$ scores and calculated the correlation $\mathbf{r}$ (see Table 2).

Table 2

\section{$\mathrm{p}, \mathrm{z}$ and $\mathbf{r}$ Values}

\begin{tabular}{clcccc}
\hline Study & \multicolumn{1}{c}{ Authors } & Year & $\mathbf{p}$ & $\mathbf{z}$ & $\mathbf{r}$ \\
\hline \multirow{2}{*}{ A } & Lee and Griffith & 2004 & 0.001 & 3.09 & 0.41 \\
& & & 0.003 & 2.75 & 0.36 \\
B & O'Cass and Julian & 2003 & NS & NA & NA \\
C & O'Donnell and Jeong & 2000 & 0.010 & 2.33 & 0.22 \\
D & Özsomer and Simonin & 2004 & 0.050 & 1.64 & 0.12 \\
& & & 0.050 & 1.64 & 0.13 \\
\hline
\end{tabular}


Table 2 (continued)

\begin{tabular}{|c|c|c|c|c|c|}
\hline Study & Authors & Year & $\mathbf{p}$ & $\mathbf{z}$ & $\mathbf{r}$ \\
\hline $\mathrm{E}$ & Johnson and Arunthanes & 1995 & 0.061 & 1.55 & 0.11 \\
\hline \multirow{2}{*}{$\mathrm{F}$} & \multirow{2}{*}{ Shoham } & \multirow{2}{*}{1999} & 0.050 & 1.64 & 0.17 \\
\hline & & & 0.050 & 1.64 & 0.17 \\
\hline G & Samiee and Roth & 1992 & NS & NA & NA \\
\hline \multirow{2}{*}{$\mathrm{H}$} & \multirow{2}{*}{ Zou and Cavusgil } & \multirow{2}{*}{2002} & 0.010 & 2.33 & 0.12 \\
\hline & & & 0.050 & 1.64 & 0.15 \\
\hline \multirow{3}{*}{ I } & \multirow{2}{*}{ Calantone et al. } & \multirow{3}{*}{2004} & 0.050 & 1.64 & 0.11 \\
\hline & & & 0.050 & 1.64 & 0.09 \\
\hline & \multirow{3}{*}{ Calantone et al. } & & 0.010 & 2.33 & 0.15 \\
\hline \multirow[t]{2}{*}{$\mathrm{J}$} & & \multirow[t]{2}{*}{2006} & 0.010 & 2.33 & 0.19 \\
\hline & & & 0.010 & 2.33 & 0.13 \\
\hline K & Dow & 2006 & 0.040 & 1.75 & 0.18 \\
\hline $\mathrm{L}$ & Cavusgil and Zou & 1994 & NS & NA & NA \\
\hline M & Lages and Montgomery & 2005 & NS & NA & NA \\
\hline $\mathrm{N}$ & Julian and O'Cass & 2004 & 0.050 & 1.64 & 0.10 \\
\hline $\mathrm{O}$ & Okazaki et al. & 2006 & NS & NA & NA \\
\hline $\mathrm{P}$ & Lages and Montgomery & 2004 & NS & NA & NA \\
\hline \multirow{4}{*}{ Q } & \multirow{4}{*}{ Lages et al. } & \multirow{4}{*}{2008} & 0.050 & 1.64 & 0.18 \\
\hline & & & 0.050 & 1.64 & 0.18 \\
\hline & & & 0.050 & 1.64 & 0.18 \\
\hline & & & 0.010 & 2.33 & 0.25 \\
\hline $\mathrm{R}$ & Schilke et al. & 2009 & 0.010 & 2.33 & 0.11 \\
\hline S & Chung & 2009 & 0.100 & 1.28 & 0.15 \\
\hline \multirow{4}{*}{$\mathrm{T}$} & \multirow{4}{*}{ Sousa and Lengler } & \multirow{4}{*}{2009} & 0.100 & 1.28 & 0.09 \\
\hline & & & 0.010 & 2.33 & 0.16 \\
\hline & & & 0.050 & 1.64 & 0.12 \\
\hline & & & 0.010 & 2.33 & 0.16 \\
\hline $\mathrm{U}$ & Wua and Cheng & 2009 & 0.010 & 2.33 & 0.13 \\
\hline \multirow[t]{2}{*}{$\mathrm{V}$} & Hultman et al. & 2009 & NS & NA & NA \\
\hline & & & 0.050 & 1.64 & 0.10 \\
\hline \multirow[t]{2}{*}{$\mathrm{W}$} & Tantong et al. & 2010 & NS & NA & NA \\
\hline & & & NS & NA & NA \\
\hline
\end{tabular}

Note. $\mathrm{NS}=$ not specified; $\mathrm{NA}=$ not applicable.

Studies B, G, L, O, P, V, and W did not present a p_value, nor indicate a similar or comparable parameter. Thus, the effect size calculation was not possible. Studies $\mathrm{C}, \mathrm{H}, \mathrm{J}, \mathrm{V}$, and $\mathrm{W}$ did not show specific $\mathrm{p}$ _values, although they did indicate the parameter $\mathrm{p}<.01$. Thus, we converted the values $\mathrm{p}<.01$ into $\mathrm{z}$ scores. The same was done on studies $\mathrm{D}, \mathrm{F}, \mathrm{H}, \mathrm{I}$, and $\mathrm{N}$, except that in these cases the parameter indicated was $\mathrm{p}<.05$. Study M proposed a positive relationship between price adaptation 
and performance. However, the test of the hypothesis in this study showed a significant negative effect for this relationship (linear regression coefficient). Thus, this study was not included in the metaanalysis because the relationship between price adaptation and performance based on study $M$ was contrary to the ones hypothesized in our research. Study V and W posited hypotheses that product adaptation and performance were positively related, but the test of hypothesis of these studies was not significant. Therefore, they were not included in the meta-analysis. It is imperative to emphasize that the effect size is calculated on the basis of equivalent hypotheses from dissimilar studies. This is the reason for the exclusion of the studies $\mathrm{M}, \mathrm{V}$ and $\mathrm{W}$ from our meta-analysis.

Next we calculated the correlation coefficients, estimating separately the mean values for each of the proposed hypotheses. The results (or effect sizes) can be seen in Table 3, as well as the list of papers used to calculate each hypothesis. In order to interpret the effect sizes, we considered the following parameters, from Cohen (1988): small effect size (up to $r=.10$ ), medium effect size (up to $r$ $=.30)$ and large effect size $(r=.50$ or more $)$.

H1a hypothesized that the standardization of the company's product, in international markets, affects its performance positively. The statistical tests found a correlation - or effect size - of .134. Hence, the hypothesis was accepted and the strength of this relationship was medium. H1b proposed that the standardization of promotion, in the international environment, positively affects the performance of the organization. The tests showed the same results, i.e., a correlation of .134. Consequently, this hypothesis was equally accepted, also revealing a medium strength. H1c proposed that the standardization of distribution, in the external environment, affects performance positively. The tests found a correlation of .133, which leads to the acceptance of the hypothesis, attributing a medium strength to it. H1d suggested that the standardization of the price, in international markets, positively affects the performance of the company. The tests also presented a correlation of medium strength (.133), which confirms this hypothesis too. The similarity between the scores of hypotheses $\mathrm{H} 1 \mathrm{a}, \mathrm{H} 1 \mathrm{~b}, \mathrm{H} 1 \mathrm{c}$ and $\mathrm{H} 1 \mathrm{~d}$ is a result of the studies included in meta-analysis. Articles C, D, H, N, R, and $\mathrm{U}$ tested for just one hypothesis the effect of standardization of the marketing mix (product, promotion, distribution and price) on performance. Article $\mathrm{S}$ tested, in a combined hypothesis, the standardization of product and promotion on performance ( $\mathrm{H} 1 \mathrm{a}$ and $\mathrm{H} 1 \mathrm{~b})$, but not the standardization of distribution and price (H1c and H1d). This explains the small difference between the values obtained in H1a and H1b, compared with those of H1c and H1d.

In short, the effect size of the four hypotheses related to standardization was very similar - but not identical - because the sub-sample used to calculate them was almost the same, with the exception of study S. Furthermore, some of them did not provide accurate p_values, as well as statistical significance (i.e., $\mathrm{p}<.01$ or $\mathrm{p}<.05)^{(2)}$, which did not allow us a more precise calculation of the effect size.

H2a suggested that adaptation of the product in the external environment affects its performance positively. We have found a correlation of .154, thus the hypothesis was accepted, showing a medium effect. $H 2 b$ suggested that the adaptation of promotion in the external market affects performance positively. The correlation was also medium (.155), driving us to accept this hypothesis too. H2c suggested that the adaptation of distribution in the international market affects performance positively. The statistical test showed a correlation of .141, again a medium strength, which also confirms the hypothesis. Finally, H2d suggested that the adaptation of price in the international environment affects performance positively. The tests demonstrated the existence of a medium strength of .209, which likewise confirms the last hypothesis, also showing a medium magnitude for the influence - the largest effect size found in all statistical tests.

In summary, the estimated effect sizes suggest the existence of a medium strength (ranging from .133 to .209); all influencing the relationships between the standardization and adaptation of the marketing mix and the performance of a company (see Table 3 ). 
Table 3

Results

\begin{tabular}{ccccccc}
\hline Hypothesis & $\begin{array}{c}\text { Number } \\
\text { of studies }\end{array}$ & $\begin{array}{c}\text { List of } \\
\text { Studies }\end{array}$ & $\mathbf{P}^{\mathbf{a}}$ & $\mathbf{Z}^{\mathbf{b}}$ & $\mathbf{E s}^{\mathbf{c}}$ & $\begin{array}{c}\text { Test of } \\
\text { hypothesis }\end{array}$ \\
\hline H1a & 7 & C, D, H, N, R, S, U & $.01-.05$ & $1.64-2.33$ & 0.134 & $\checkmark$ \\
H1b & 7 & C, D, H, N, R, S, U & $.01-.1$ & $1.28-2.33$ & 0.134 & $\checkmark$ \\
H1c & 6 & C, D, H, N, R, S & $.01-.05$ & $1.64-2.33$ & 0.133 & $\checkmark$ \\
H1d & 6 & C, D, H, N, R, S & $.01-.05$ & $1.64-2.33$ & 0.133 & $\checkmark$ \\
H2a & 9 & A, E, F, I, J, K, N, Q, T & $.001-.1$ & $1.28-3.09$ & 0.154 & $\checkmark$ \\
H2b & 5 & F, K, N, Q, T & $.01-.05$ & $1.64-2.33$ & 0.155 & $\checkmark$ \\
H2c & 4 & K, N, Q, T & $.04-.05$ & $1.64-1.75$ & 0.141 & $\checkmark$ \\
H2d & 5 & A, K, N, Q, T & $.003-.05$ & $1.64-2.75$ & 0.209 & $\checkmark$ \\
\hline
\end{tabular}

Note. ${ }^{a}$ These numbers refer to the lowest and highest value indicated on the samples; ${ }^{b}$ These numbers refer to the lowest and highest score resulting from the conversion; ${ }^{\mathrm{c}} \mathrm{ES}=$ effect size

\section{Discussion and Conclusions}

Both views of standardization and adaptation seem logic and coherent. However, the heterogeneity of the markets does not allow total standardization, and the high costs of adaptation do not allow its use for the whole marketing mix. Marketers seem to avoid the polarization of these strategies since their extreme use is not beneficial. This initiative is defended by some authors who reject the application of a single strategy for all markets (Cavusgil et al., 1993; Jain, 1989; Sorenson \& Wiechmann, 1975; Vrontis, 2003; Vrontis \& Kitchen, 2005; Vrontis \& Papasolomou, 2005; Walters, 1986). Perhaps one of the reasons that make this an ongoing debate is that both schools assume their own perspective as being unique and superior.

Interestingly, the results of our meta-analysis support the existence and importance of both views, because we have found positive relationships between both the adaptation and the standardization of the marketing mix, when related to performance. The results, however, suggest that companies should slightly emphasize the adaptation of their marketing mix $(E S$ mean $=.168)$ instead of standardizing it (ES mean $=.134$ ) when entering into a new international market. Although statistically significant, the difference between both strategies is small (.034) and should, thus, be used with caution by marketers when deciding to adopt one strategy instead of other.

While separately analyzing each of the variables of the marketing mix, we have found that the price adaptation is, among all the marketing mix variables, the one that should be focused on the most, as it resulted in the largest effect size of all tested hypothesis $(E S=.209)$. This result is different from previous research (e.g. Shoham, 2002) that had disconfirmed the adaptation of price impact on performance and somehow showed a different perspective for marketers. Nevertheless, one should note that Shoham's (2002) article studied the relationship between price and performance with a different perspective than ours, as earlier commented. Even considering that our meta-analysis is more recent and somehow different from Shoham's, such emphasis on price adaptation is something that should receive more attention in future research.

The adaptation of product $(\mathrm{ES}=.154)$ and promotion $(\mathrm{ES}=.155)$ should also be considered as more important than distribution adaptation $(\mathrm{ES}=.141)$. These results are also different from previous studies. For example, Theodosiou and Leonidou (2003) posit - based on a literature review - that 
adaptation of promotion, price and distribution have an impact on performance, and that product standardization is related to performance. Our results are also different from Shoham's (2002), as he found that product and promotion adaptation strategies are more important than price and distribution strategies, when considering their impact on performance.

The relative similarity and magnitude of the meta-analysis results show that the main decision a marketer should take is not necessarily which of the strategies to apply, nor which one to privilege, but the intensity of the strategy used. Here, the organization also has to consider its common strategy, the environment and market orientation. In general, cost reductions and market complexity are the most common impetus for standardization, whereas the necessity to take care of the particular needs of each market is a frequent reason for adaptation. Our results also show that both strategies can coexist and cause effects on performance. Therefore, the core choice is "how much", i.e., to what degree should each strategy be used (Cavusgil \& Zou, 1994; Jain, 1989, 2007).

Some practical examples can illustrate these recommendations. For example, companies such as Nike, Levi's and Coca-Cola are considered global, and they tend to see the world as a single market. But even these companies have adapted their marketing mix, sometimes in a subtle way (Gupta \& Govindarajan, 2001; Vignali, 2001). Coca-Cola, for instance, sells virtually the same product all over the world: Coca-Cola. However, beyond this marquee product, its major strategy is diversification of products and their adaptation, encompassing all its consumers in the 200 countries where the company operates. In Japan, one of its main markets, its products include coffee, teas and even Real, a hangover cure (Ghemawat, 2007b). The adaptations also include product descriptions, the ingredients, packing, line of products, and advertising campaigns. Although there is a prototype product, local adaptations are still made (Dana \& Vignali, 1999).

Furthermore, companies must be attentive since the need for degree of adaptation can change periodically. In many industries, factors such as the global media and decreasing incomes may pave the way toward increasing standardization. Otherwise, in industries where the product can be delivered over the Internet, such as the music industry, the need for customization may increase over time (Gupta \& Govindarajan, 2001). A similar situation is faced by Pizza Hut Inc., a company that usually adapts its products in each country where it operates (Kumar \& Goel, 2007).

Therefore, marketers might use the results shown here in our meta-analysis as guidance, since we have used empirical data collected from companies that have faced the internationalization process. Our results, thus, can be compared to the actual practices adopted by the organizations. Differences found lead to a deeper reflection concerning the strategies, the improvement of tactics, or the implementation of a new behavior. Aware of the relationship between adaptation, standardization and performance, companies should adjust themselves considering their interests, objectives, market proximity, target market, and customers' needs. It seems essential that marketers visualize the tenuous line between standardization and adaptation, especially regarding performance.

Overall, the most important conclusion of our meta-analysis is that organizations can achieve greater performance if they do not consider the world as a single market. It may be that standardization should only be adopted in situations where it would not compromise performance, market orientation and consumer satisfaction. Besides, we have found that each component of the marketing mix demands different degrees of the chosen strategy. The important decision - we suggest - is to balance the strategy level and the market needs. As Cavusgil et al. (1993) pointed out, to determine this level some aspects must be observed, such as technology, culture, competition, and international experience. The level should be defined by the degree of adaptation required to operate in the market, considering the characteristics of each place in which the company will operate. Whatever the decision is, it should also take into account financial returns, which involve competitive advantage and performance. As Theodosiou and Leonidou (2003, p. 167) affirmed, "international marketing strategy - whether standardized or adapted - will lead to superior performance only to the extent that it properly matches the unique set of circumstances that the firm is confronted by within a particular overseas market". We hope our study fulfills some gaps of the literature and, most importantly, helps marketers to decide about some courses of action when dealing with the internationalization process. 


\section{Limitations and future research}

A meta-analysis provides an opportunity for shared subjectivity in reviews, rather than true objectivity. Authors that use meta-analyses must sometimes make decisions based on their own judgment, such as when defining the boundaries of the analysis or deciding exactly how to code moderator variables. However, meta-analysis requires that these decisions are made public so they are open to criticism from other scholars (DeCoster, 2004). Thus, one important issue on conducting a meta-analysis is to consider its limitations.

For Sobrero and Schrader (1998), this methodology should be viewed carefully, considering that: (a) the previous studies could have been conducted with different relationships between constructs or variables, and the framework on which each study was based can determine different impact on the effect size; (b) the methodology applied, and problems in the constructs validity and reliability can also impact the meta analyzed results; and (c) the search technique and the availability of studies are also some limitation on every meta-analysis. Indeed, some studies included in our metaanalysis presented different constructs, variables, and even methodologies.

Other important consideration about a meta-analysis is that it requires a sample of articles in which the same hypotheses are tested. In some of the articles we analyzed the hypotheses were sometimes grouped or, in some cases, tested in relation to other constructs, what might have somehow influenced the results.

In spite of the acceptance of all the hypotheses, all results we have found showed a medium magnitude, but closer to a small one. However, we believe they can be used as guides of action because, as Cohen (1988) argues:

The terms 'small', 'medium', and 'large' are relative, not only to each other, but to the area of behavioral science or even more particularly to the specific content and research method being employed in any given investigation.... In the face of this relativity, there is a certain risk inherent in offering conventional operational definitions for these terms for use in power analysis in as diverse a field of inquiry as behavioral science. This risk is nevertheless accepted in the belief that more is to be gained than lost by supplying a common conventional frame of reference which is recommended for use only when no better basis for estimating the ES index is available (p. 25).

After conducting this meta-analysis, it became evident that some subjects require more research, such as the use of quantitative methods to: (a) measure the degree of adaptation within a determined segment; (b) measure the need for standardization within a specific segment; (c) understand possible differences in the application of these practices in different segments; (d) measure the level of adaptation actually employed in different segments and markets; (e) compare results of home vs. host regions, manufacturing vs. service sectors, etc.; (f) incorporate moderation variables to study contingent effects; (g) identify variables that may influence the decision making process; (h) utilize other statistics parameters to calculate the effect size in a more precise way.

Moreover, our theoretical revision of the performance construct was focused on how the international marketing papers have analyzed it, what is different - one might say less accurate compared with papers that have dealt exclusively with the performance construct. Thus, we also recommend that future studies consider a more detailed analysis of this construct (see Carneiro et al., 2005 for a detailed review of it).

Some qualitative research might also help to understand the problem, which could analyze: (a) internal elements that influence the choice of one strategy over another; (b) external elements that influence the choice of one strategy over another; (c) the influence of entry strategy on the decision to standardize or to adapt; (d) the marketing practices adopted by some companies in determined segments; (e) similarities and differences between organizations of various segments; (f) similarities and differences between companies in the same segment; (g) the level of adaptation employed by 
certain companies; and (h) the influence of culture on standardization and adaptation strategies. In short, the subject still requires more research; from the entry strategy to the international marketing strategy that brings the best results, and especially as to how it reflects on performance.

\section{Received 29 June 2009; received in revised form 11 April 2011.}

\section{Notes}

\footnotetext{
${ }^{1}$ This article does not analyze entry strategies, nor internal and external aspects of the internationalization.

${ }^{2}$ A conservative decision was taken as to use the values $\mathrm{p} \leq .01 \mathrm{e} \mathrm{p} \leq .05$ when the original article presented values lower than or equal to .01 and .05 , respectively.
}

\section{References}

Amine, L. S., \& Cavusgil, S. T. (2001). Export marketing strategies in the British clothing industry. European Journal of Marketing, 20(7), 21-33. doi: 10.1108/EUM0000000004653

Ang, Z., \& Massingham, P. (2007). National culture and the standardization versus adaptation of knowledge management. Journal of Knowledge Management, 11(2), 5-21. doi: $10.1108 / 13673270710738889$

Baalbaki, I. B., \& Malhotra, N. K. (1993). Marketing management bases for international market segmentation: an alternate look at the standardization/customization debate. International Marketing Review, 10(1), 19-44. doi: 10.1108/02651339310025839

Barney, J. B. (1996). Gaining and sustaining competitive advantage. New York: Addison-Wesley.

Calantone, R. J., Cavusgil, S. T., Schmidt, J. B., \& Shin, G.-C. (2004). Internationalization and the dynamics of product adaptation - an empirical investigation. Journal of Product Innovation Management, 21(3), 185-198. doi: 10.1111/j.0737-6782.2004.00069.x

Calantone, R. J., Kim, D., Schmidt, J. B., \& Cavusgil, S. T. (2006). The influence of internal and external firm factors on international product adaptation strategy and export performance: a three-country comparison. Journal of Business Research, 59(2), 176-185. doi: 10.1016/j.jbusres.2005.05.001

Carneiro, J. M. T., Silva, J. F., Rocha, A., \& Hemais, C. A. (2005, June). Mensuração do desempenho organizacional: questões conceituais e metodológicas. Proceedings of the Encontro de Estudos em Estratégia, Rio de Janeiro, RJ, Brazil, 2.

Cavusgil, S. T., \& Zou, S. (1994). Marketing strategy-performance relationship: an investigation of the empirical link in export market ventures. Journal of Marketing, 58(1), 1-21.

Cavusgil, S. T., Zou, S., \& Naidu, G. M. (1993). Product and promotion adaptation in export ventures: an empirical investigation. Journal of International Business Studies, 24(3), 479-506. doi: 10.1057 palgrave.jibs. 8490242

Chung, H. (2009). Structure of marketing decision making and international marketing standardisation strategies. European Journal of Marketing, 43(5-6), 794-825. doi: $10.1108 / 03090560910947052$ 
Cohen, J. (1988). Statistical power analysis for the behavioral sciences (2nd ed.). Hillsdale, NJ: Lawrence Erlbaum Associates.

Colpan, A. M. (2006). Dynamic effects of product diversity, international scope and Keiretsu membership on the performance of Japan's textile firms in the 1990s. Asian Business and Management, 5(3), 419-445. doi: 10.1057/palgrave.abm.9200193

Conant, J. S., \& White, J. C. (1999). Marketing program planning, process benefits, and store performance: an initial study among small retail firms. Journal of Retailing, 75(4), 525-541. doi: $10.1016 / \mathrm{S} 0022-4359(99) 00017-2$

Cooper, H., \& Hedges, L. V. (1999). The handbook of research synthesis. London: Sage Publications.

Dana, L. P., \& Vignali, C. (1999). Lublin Coca-Cola bottlers Ltd. British Food Journal, 101(5-6), 447-455. doi: 10.1108/00070709910278424

DeCoster, J. (2004). Meta-analysis notes. Retrieved July 9, 2009, from http://www.stathelp.com/notes.html

Doole, I., Grimes, T., \& Demack, S. (2006). An exploration of the management practices and processes most closely associated with high levels of export capability in SEMs. Marketing Intelligence and Planning, 24(6), 632-647. doi: 10.1108/02634500610701690

Dow, D. (2006). Adaptation and performance in foreign markets: evidence of systematic underadaptation. Journal of International Business Studies, 37(2), 212-226. doi: 10.1057/palgrave.jibs.8400189

Elinder, E. (1965). How international can European advertising be? Journal of Marketing, 29(2), 7-11.

Farley, J. U., Lehmann, D. R., \& Sawyer, A. (1995). Empirical marketing generalization using metaanalysis. Marketing Science, 14(3), 36-46. doi: 10.1287/mksc.14.3.G36

Florin, J., \& Ogbuehi, A. O. (2004). Strategic choice in international ventures: a contingency framework integrating standardization and entry-mode decisions. Multinational Business Review, 12(2), 83-109.

Francis, J., \& Collins-Dodd, C. (2004). Impact of export promotion programs on firm competencies, strategies and performance. International Marketing Review, 21(4-5), 474-495. doi: $10.1108 / 02651330410547153$

Ghemawat, P. (2007b). Coca-Cola's global rethink. Retrieved January 12, 2009, from http://discussionleader.hbsp.com/ghemawat/2007/10/cocacolas_global_rethink.html

Ghemawat, P. (2007a). Managing differences: the central challenge of global strategy. Harvard Business Review, 85(3), 59-68.

Ginsberg, A. (1984). Operationalizing organizational strategy: toward an integrative framework. Academy of Management Review, 9(3), 548-557. doi: 10.5465/AMR.1984.4279708

Gupta, A. K., \& Govindarajan, V. (2001). Converting global presence into global competitive advantages. The Academy of Management Executive, 15(2), 45-58. doi: 10.5465/AME.2001.4614881

Hultman, M., Robson, M., \& Katsikeas, C. (2009). Export product strategy fit and performance: an empirical investigation. Journal of International Marketing, 17(4), 1-23. doi: $10.1509 /$ jimk.17.4.1 
Jain, S. C. (1989). Standardization of international marketing strategy: some research hypotheses. Journal of Marketing, 53(1), 70-79. doi: 10.2307/1251525

Jain, S. C. (2007). State of the art of international marketing research: directions for the future. Journal of Global Business Advancement, 1(1), 4-19. doi: 10.1504/JGBA.2007.012546

Jitpaiboon, T., \& Rao, S. S. (2007). A meta-analysis of quality measures in manufacturing system. International Journal of Quality and Reliability Management, 24(1), 78-102. doi: $10.1108 / 02656710710720349$

Johnson, J. L., \& Arunthanes, W. (1995). Ideal and actual product adaptation in U.S. exporting firms: market-related determinants and impact on performance. International Marketing Review, 12(3), 31-46. doi: 10.1108/02651339510091726

Julian, C. C. (2003). Export marketing performance: a study of Thailand firms. Journal of Small Business Management, 41(2), 213-221. doi: 10.1111/1540-627X.00077

Julian, C. C., \& O'Cass, A. (2002). Drivers and outcomes of export marketing performance in a developing country context. Journal of Asia Pacific Marketing, 1(2), 1-21.

Julian, C. C., \& O'Cass, A. (2004). The antecedents of export marketing performance: an Australian perspective. Journal of Asia Pacific Marketing, 3(2), 99-113.

Kaplan, R. S., \& Norton, D. P. (1992). The balanced scorecard - measures that drive performance. Harvard Business Review, 70(1), 71-79.

Kazem, A., \& Heijden, B. V. D. (2006). Exporting firms' strategic choices: the case of Egyptian SEMs in the food industry. S.A.M. Advanced Management Journal, 71(3), 21-33.

Kemppainen, K., Vepsäläinen, A. P. J., \& Tinnilä, M. (2008). Mapping the structural properties of production process and product mix. International Journal of Production Economics, 111(2), 713-728. doi: 10.1016/j.ijpe.2007.03.020

Kogut, B. (1989). Research notes and communications: a note on global strategies. Strategic Management Journal, 10(4), 383-389. doi: 10.1002/smj.4250100407

Kotler, P. (1986). Global standardization - courting danger. Journal of Consumer Marketing, 3(2), 1315. doi: $10.1108 / \mathrm{eb} 008158$

Kumar, S., \& Goel, B. (2007). Glocalization in food and agribusiness: strategies of adaptation to local needs and demands. Retrieved January 12, 2009, from https://www.ifama.org/events/conferences/2007/cmsdocs/1135_Paper.pdf

Lages, L., Abrantes, J., \& Lages, C. (2008). The STRATADAPT scale: a measure of marketing strategy adaptation to international business markets. International Marketing Review, 25(5), 584-600. doi: 10.1108/02651330810904107

Lages, L. F., \& Montgomery, D. B. (2004). Export performance as an antecedent of export commitment and marketing strategy adaptation - evidence from small and medium-sized exporters. European Journal of Marketing, 38(9-10), 1186-1214. doi: $10.1108 / 03090560410548933$

Lages, L. F., \& Montgomery, D. B. (2005). The relationship between export assistance and performance improvement in Portuguese export ventures. European Journal of Marketing, 39(7-8), 755-784. doi: 10.1108/03090560510601752 
Laroche, M., Kirpalani, V. H., Pons, F., \& Zhou, L. (2001). A model of advertising standardization in multinational corporations. Journal of International Business Studies, 32(2), 249-266. doi: 10.1057/palgrave.jibs.8490951

Lee, C., \& Griffith, D. A. (2004). The marketing strategy-performance relationship in an export-driven developing economy. International Marketing Review, 21(3), 321-334. doi: $10.1108 / 02651330410539648$

Leonidou, L. C., Katsikeas, C. S., \& Samiee, S. (2002). Marketing strategy determinants of export performance: a meta-analysis. Journal of Business Research, 55(1), 51-67. doi: 10.1016/S01482963(00)00133-8

Levitt, T. (1983). The globalization of markets. Harvard Business Review, 61(3), 92-102.

Levitt, T. (1986). Marketing imagination. New York: Simon \& Schuster.

Lim, L. K. S., Acito, F., \& Rusetski, A. (2006). Development of archetypes of international marketing strategy. Journal of International Business Studies, 37(4), 499-524. doi: $10.1057 /$ palgrave.jibs. 8400206

McNaughton, R. B. (2002). The use of multiple export channels by small knowledge-intensive firms. International Marketing Review, 19(2), 190-203. doi: 10.1108/02651330210425033

Myers, M. B., Cavusgil, S. T., \& Diamantopoulos, A. (2002). Antecedents and actions of export pricing strategy: a conceptual framework and research propositions. European Journal of Marketing, 36(1-2), 159-188. doi: 10.1108/03090560210412746

Myers, M. B., \& Harvey, M. (2001). The value of pricing control in export channels: a governance perspective. Journal of International Marketing, 9(4), 1-29. doi: 10.1509/jimk.9.4.1.19941

Newburry, W., \& Yakova, N. (2006). Standardization preferences: a function of national culture, work interdependence and local embeddedness. Journal of International Business Studies, 37(1), 4460. doi: $10.1057 /$ palgrave.jibs. 8400179

O'Cass, A., \& Julian, C. (2003). Examining firm and environmental influences on export marketing mix strategy and export performance of Australian exporters. European Journal of Marketing, 37(3-4), 366-384. doi: 10.1108/03090560310459005

O’Donnell, S., \& Jeong, I. (2000). Marketing standardization within global industries - an empirical study of performance implications. International Marketing Review, 17(1), 19-30. doi: $10.1108 / 02651330010314696$

Ogunmokun, G. O., \& Esther, L. L. (2004). Product development process and performance of export ventures: a study of exporting companies in the People's Republic of China. Journal of Asia Pacific Marketing, 3(2), 84-98.

Okazaki, S., Taylor, C. R., \& Zou, S. (2006). Advertising standadization's positive impact on the bottom line. Journal of Advertising, 35(3), 17-33. doi: 10.2753/JOA0091-3367350302

Özsomer, A., Bodur, M., \& Cavusgil, S. T. (1991). Marketing standardization by multinationals in an emerging market. European Journal of Marketing, 25(12), 50-61. doi: 10.1108/EUM0000000000635

Özsomer, A., \& Simonin, B. L. (2004). Marketing program standardization: a cross-country exploration. International Journal of Research in Marketing, 21(4), 397-419. doi: 10.1016/j.ijresmar.2004.06.003 
Papavassiliou, N., \& Stathakopoulos, V. (1997). Standardization versus adaptation of international advertising strategies: towards a framework. European Journal of Marketing, 31(7), 504-527. doi: $10.1108 / 03090569710176646$

Quelch, J. A., \& Hoff, E. J. (1986). Customizing global marketing. Harvard Business Review, 64(3), 59-68.

Roostal, I. (1963). Standardization of advertising for Western Europe. Journal of Marketing, 27(4), $15-20$.

Ryans, J. K., Jr., Griffith, G. A., \& White, D. S. (2003). Standardization/adaptation of international marketing strategy. International Marketing Review, 20(6), 588-603. doi: $10.1108 / 02651330310505204$

Samiee, S., \& Roth, K. (1992). The influence of global marketing standardization on performance. Journal of Marketing, 56(2), 1-17.

Sands, S. (1979). Can you standardize international marketing strategy? Academy of Marketing Science, 7(1-2), 117-134.

Schilke, O., Reimann, M., \& Thomas, J. (2009). When does international marketing standardization matter to firm performance? Journal of International Marketing, 17(4), 24-46. doi: $10.1509 /$ jimk.17.4.24

Shamsuddoha, A. K., \& Ali, M. Y. (2006). Mediated effects of export promotion programs on firm export performance. Asia Pacific Journal of Marketing and Logistics, 18(2), 93-110. doi: $10.1108 / 13555850610658255$

Shoham, A. (1999). Bounded rationality, planning, standardization of international strategy and export performance: a structural model examination. Journal of International Marketing, 7(2), 24-50.

Shoham, A. (2002). Standardization of international strategy and export performance: a meta-analysis. Journal of Global Marketing, 16(1-2), 97-120. doi: 10.1300/J042v16n01_05

Sobrero, M., \& Schrader, S. (1998). Structuring inter-firm relationships: a meta- analytic approach. Organizations Studies, 19(4), 585-615. doi: 10.1177/017084069801900403

Sorenson, R. Z., \& Wiechmann, U. E. (1975). How multinationals view marketing standardization. Harvard Business Review, 53(3), 38-54.

Sousa, C., \& Lengler, J. (2009). Psychic distance, marketing strategy and performance in export ventures of Brazilian firms. Journal of Marketing Management, 25(5-6), 591-610. doi: 10.1362/026725709X461876

Szymanski, D. M., Bharadwaj, S. G., \& Varadarajan, P. R. (1993). An analysis of the market shareprofitability relationship. Journal of Marketing, 57(3), 1-18.

Tantong, P., Karande, K., Nair, A., \& Singhapakdi, A. (2010). The effect of product adaptation and market orientation on export performance: a survey of Thai managers. Journal of Marketing Theory and Practice, 18(2), 155-169. doi: 10.2753/MTP1069-6679180204

Theodosiou, M., \& Leonidou, L. C. (2003). Standardization versus adaptation of international marketing strategy: an integrative assessment of the empirical research. International Business Review, 12(2), 141-171. doi: 10.1016/S0969-5931(02)00094-X

Vignali, C. (2001). McDonald's: "think global, act local" - the marketing mix. British Food Journal, 103(2), 97-111. doi: 10.1108/00070700110383154 
Viswanathan, N. K., \& Dickson, P. R. (2007). The fundamentals of standardizing global marketing strategy. International Marketing Review, 24(1), 46-63. doi: 10.1108/02651330710727187

Vrontis, D. (2003). Integrating adaptation and standardization in international marketing: the AdaptStand modeling process Journal of Marketing Management, 19(3-4), 283-305.

Vrontis, D., \& Kitchen, P. J. (2005). Entry Methods and international marketing decision making: an empirical investigation. Journal of International Business Studies, 13(1), 87-110.

Vrontis, D., \& Papasolomou, I. (2005). The use of entry methods in identifying multinational companies' AdapStand behavior in foreign markets. Review of Business, 26(1), 13-20.

Walters, P. G. P. (1986). International marketing policy: a discussion of the standardization construct and its relevance for corporate policy. Journal of International Business Studies, 17(2), 55-69. doi: $10.1057 /$ palgrave.jibs. 8490424

Wolf, F. M. (1986). Meta-analysis: quantitative methods for research synthesis. London: Sage Publications.

Wua, W., \& Cheng, C. (2009). The optimal internal marketing strategy in services under open economy. Applied Economics Letters, 16(8), 841-845. doi: 10.1080/13504850701221964

Zou, S., Andrus, D. M., \& Norvell, D. W. (1997). Standardization of international marketing strategy by firms from a developing country. International Marketing Review, 14(2), 107-123. doi: $10.1108 / 02651339710170203$

Zou, S., \& Cavusgil, S. T. (2002). The GMS: a broad conceptualization of global marketing strategy and its effect on firm performance. Journal of Marketing, 66(4), 40-56. doi: $10.1509 /$ jmkg.66.4.40.18519 